\title{
Encouraging Postgraduate Dissertation Students' Deep Reflection-on-Learning: A Case for a Reflective Approach to Evaluating Students' Learning
}

\author{
Mark A. Minott \\ Independent Researcher, 289 Norwood Road, SE24 9AQ London, United Kingdom
}

\begin{abstract}
Over the past 30 years, the teaching profession has embraced the notion of the teacher as a reflective practitioner, which has led to an increased emphasis on teacher education programs offering learning experiences that model and encourage reflective practice. Since that time, the idea of reflection has permeated all facets of education, including the dissertation supervision process. This action research study explored the usefulness of a modified version of an exercise called the reflective approach to teaching practicum debriefing (RATPD) to encourage postgraduate dissertation students' deep reflection on learning, primarily what they learned about research writing and dissertation supervision. While the RATPD strategy is a useful approach for encouraging student teachers' deep reflection-on-learning, what was unknown, was its usefulness as a debriefing tool for postgraduate students who have completed their dissertation. Examples of the usefulness of the approach include the fact that (1) it encouraged postgraduate dissertation students to focus on the mechanics and affective of research writing and dissertation supervision and also consider "self as researcher" and (2) it encouraged students' criticality and internalisation reflected in taking ownership of positive attitudes and behaviours - associated with the experience of research writing and dissertation supervision - as a part of their nature.
\end{abstract}

Keywords: Thesis supervision; dissertation supervision; education; reflection; reflective learning and teaching; evaluation; University; students

DOI: $10.7176 / \mathrm{JEP} / 10-33-06$

Publication date: November $30^{\text {th }} 2019$

\section{Introduction and Rationale}

This action research study aimed to ascertain the usefulness of a modified version of the reflective approach to teaching practice debriefing (RATPD) strategy in encouraging postgraduate dissertation students' deep reflection-on-learning.

This study is important for two reasons. Firstly, it contributes to the existing body of knowledge regarding the efficacy of reflective learning and teaching. Secondly, it provides postgraduate dissertation supervisors in all disciplines with a useful, practical, user-friendly reflective tool for evaluating students' learning.

This paper commences with a discussion of learning generally, learning by reflecting on the dissertation supervision process, evaluating students' learning, and of the particular reflective approach utilised-not just to evaluate students' learning - but to encourage their ability to reflect-on-learning. Next, the research which formed the basis of the paper is outlined and the findings and conclusions presented.

\section{Discussion of Key Concepts}

\subsection{Learning (generally)}

While there is some consensus about learning being a process, there is no single universally accepted definition of the term, and there seems to be no agreement among scholars on this matter. However, there are a few common characteristics noted in the myriad of definitions, primarily the fact that it is about change in behaviour and is the product of an interaction between the person and the environment (Jarvis, 1996; Merriam and Caffarella, 1999). Merriam and Caffarella (1999) expand on this idea when they state that this way of thinking about learning is supported by social learning theory which posits that in addition to the behavioural and cognitive aspects associated with learning, people also learn by observing what takes place in a social setting. Jarvis (1996) is of the opinion that learning is a process. He is not alone in this understanding of learning; see, for example, McCulloch (2009), who sees learning as a process in which the student is involved in an ongoing engagement with the subject matter, the process of studying, and dialogue with other students.

What has been hinted at in the foregoing discussion is the development of the mind as integral to the learning process and the mind is formed when the brain begins to store a variety of experiences. In like manner, the 'self' (i.e., the ability to think, interpret sensations and give meaning to situations or events) which is also integral to the learning process, is formed as we have every day experiences. This idea is highlighted by Merriam and Caffarella (1999). These writers refer to the idea as cognitive orientation or information processing learning theory. The theory states that learning should not be viewed as primarily a stimulus-response activity, but as an activity involving thinking, interpreting sensations and giving meaning to situations or events. From birth, 
humans interact with others in sociocultural environments and process information; these interactions also help to form 'self'. Jarvis (1996) states that learning involves encountering and understanding everyday experiences, internalising them and making them a part of us (self). Learning, however, does not only involve internalisation but externalisation, where the individual's learned social characteristics interact with his/her environment. Social situations then provide avenues through which learning occurs (Gomez \& Rico, 2007). An individual can respond to a social situation in one of two ways, by taking action to learn from it or withdrawing, in which case, non-learning occurs. An active response to a social situation will eventually facilitate some degree of learning.

In summary, learning involves information processing and occurs through experience and interaction with a sociocultural milieu. All learning begins with some experience, primary or secondary. Primary experiences are immediate and personal, secondary experiences are relayed information or experiences that might be someone's interpretation of an event or situation; and since learning occurs through experiences in a social situation, the individual's perception of that situation gives meaning to the experience (Long, 1990). This summary provides a useful framework for our brief discussion of how people learn by reflecting on the dissertation supervision process

\subsection{Learning by reflecting on the dissertation supervision process}

The summary suggests that to learn involves information processing, primary and secondary experiences and interaction with a sociocultural milieu. Firstly, it is now a fact that reflection is a cognitive activity that requires the ability to mentally process information. Vilkinas (2008) studying the supervision of Ph.D./Research Students' Theses made the point that, for dissertation supervisors, the ability to reflect on practice provide opportunities to learn from previous experiences and to inform future behaviours and to assess their performance critically, reflect on their assessment, and learn from it thus constantly improving their academic supervision capability. The activities outlined here by Vilkinas (2008) are all cognitive and involves the processing of information about various aspects of the dissertation supervision process. While it is excellent that dissertation supervisors engage in reflection to learn, Naydene, Guruvasagie, and Vitallis (2011) speaking about supporting doctoral learning states that it is also a role of the supervisor to enable the student to reflect on, and analyse own work. It is this cognitive processing of information, which is the focus of this study, as participants did engage in mental processing which (as will be shown later) was displayed in their responses to the questions asked during the employment of the modified RATPD strategy.

Secondly, the summary also points out that learning involves both primary and secondary experiences. Primary experiences are immediate and personal and secondary experiences are relayed information (Long, 1990). Primary and secondary experiences are inextricable facets of the dissertation supervision process. This is so because, at various stages, the student will have primary experiences taking the form of interacting with the supervisor, carrying out a literature search and review and writing the actual dissertation. The student will also have secondary experiences, for example, the supervisor relaying information which may include recommending a particular methodology or commenting and suggest changes to a draft chapter.

Thirdly, learning also involves interaction with a sociocultural milieu. In other words, the resources that are available to students and the teaching approach utilised by supervisors such as the apprenticeship approach Albertyn and Bitzer (2011) and task focused, Vilkinas (2008), are aspects of the milieu which aid learning.

Given the nature of learning generally, and specifically learning via reflection in the dissertation supervision process, how should students' learning be evaluated? This is the focus in the next section of this paper. Answers to this question are important since fundamentally, this study is about evaluating students' learning but doing so using a reflective strategy.

\subsection{Evaluating students' learning in the dissertation supervision process}

Ferris and Hedgcock (1998) state that through regular evaluation, the teacher is better able to prepare work with students' learning needs in mind and will be able to address individual problems when they arise. Moreover, the process, if carried out effectively, will eventuate into students' progress and the improvement of teaching (James-Reid, 1983). While this can be true of the dissertation supervision i.e., evaluation of the dissertation supervision process can lead to the supervisor being prepare to address individual problems and improve the supervision process, Yousefl, Bazrafkan, and Yamani (2015) in their study of the dissertation supervision process in medical education in Iran, state that ineffective evaluation of students and their writing occurs. A critical element of the evaluation process is reflection in and on action and students' and supervisor underutilization of these aspects of evaluation can result in several challenges in the research supervision process. The writers did not highlight examples of these specific challenges.

Having said these, self-evaluation seems to feature prominently in the literature which examines evaluating students' learning in the dissertation supervision process. For example, Vilkinas, (2008) arguing for an 'integrator's model' of dissertation supervision implies that supervisors should themselves first engage in selfevaluation by observing his or her behaviour and reflecting on the observations and doing so, leads to personal 
and scholarly growth and development as educators. Maunder, Gordon-Finlayson Callaghan (2012) exploring the supervision of Master's students undertaking qualitative research dissertations made the point that one role of the supervisor is to 'scaffold' students' learning by encouraging them to self-evaluate by reflecting on own ideas, defending decisions made and act on feedback provided.

Writers such as Rowe (1984), James-Reid (1983) and Ferris and Hedgcock (1998) all agree that students' learning and their responses to learning activities need to be evaluated. These writers and others, like Bryant (1992), also agree that written or mental records should be made of skills students have acquired and those on which they are working. This suggests the need for a system or method of recording the skills students have acquired or those on which they are working.

This is important, for this study is not only concerned with a strategy for recording skills students learned but (as will be shown later in this paper) with encouraging a written reflective approach to the process.

According to Sparapani (2000), questions regarding students' response to various learning activities are central to the evaluation process. However, these questions should not only focus on the achievement of cognitive skills but also on the affective.

From the foregoing discussion, it seems the use of written records of students' evaluation and the use of questions which help to solicit learned cognitive and affective skills, are critical elements of the process of evaluating their learning. Minott (2012), took up these ideas and activities and utilised them in his reflective approach to teaching practice debriefing (RATPD).

\section{What Constitutes the RATPD?}

At its core, the reflective approach to teaching practicum debriefing (RATPD) as it is originally titled, is a student-centred evaluation strategy aimed at encouraging student teachers to reflect-on-learning. The approach is grounded in Schön's (1983) reflection-on-action and the idea of Zeichner and Liston (1996) which states that reflective learning and teaching must involve the use of questions. The approach is utilised during student teachers' practicum debriefing tutorials.

As indicated in the foregoing discussion, the use of questions is a central tenet of the RATPD. Three reflective questions make up the approach. These are:

1. What have you learned about teaching?

2. Has the observation caused any changes in your beliefs, values and assumptions about teaching?

3. What have you learned about 'self' as teacher?

For this study, the questions were modified to fit the context and participants, i.e., postgraduate dissertation students. The questions used were:

1. From your recent research writing and supervision experience, what have you learned about each aspect i.e., research writing and supervision?

2. To what extent has your recent research writing and supervision experience caused changes in your beliefs, values and assumptions about these aspects i.e., research writing and supervision?

3. What have you learned about 'yourself' as a researcher?

Minott (2012) claimed it is through these reflective questions that the RATPD strategy is enacted and which he also used to guide discussions during teaching practice debriefing sessions. He refers to the three questions as 'reflective' because firstly, they emerge from his understanding of reflective teaching. He quotes Zeichner and Liston (1996)

If a teacher never questions the goals and the values that guide his or her work, the context in which he or she teaches, or never examines his or her assumptions, then it is our belief that this individual is not engaged in reflective teaching (p. 1).

Then defines reflective teaching as involving a questioning disposition and critically thinking about one's teaching techniques, personal goals, values, beliefs, assumptions about teaching, and the teaching context. This means that the desire and willingness to question and to think critically must come naturally or be cultivated through practice. Secondly, and more importantly, they helped to encourage student teachers to critically think about what they had observed in schools during their practicum and their learning and behaviours as potential teachers.

The modified questions utilised in this study are akin to the original questions in that they encouraged the participants to examine, not just the cognitive and the affective aspects of the research dissertation supervision process, but to reflect on 'self' as a learner and more importantly, self as a researcher.

\section{Research design}

This study utilised an action research approach which allowed me to ascertain the usefulness of a modified version of the reflective approach to teaching practice debriefing (RATPD) strategy in encouraging postgraduate dissertation students' deep reflection-on-learning. Primarily what they learned about research writing and dissertation supervision. As a research framework, action research was utilised because it is an extension of 
reflective practice since critical reflection on practice feeds the research findings (Schön, 1983). It allows researchers to address issues relevant to their practice, effect change to practice, and actively involves research participants in the research process (Denscombe, 1998). Deep reflection involves critically thinking about the cognitive and affective aspects of learning and 'self' as a researcher. To achieve the study's aim required actions such as critically reflecting on the practice of research writing and dissertation supervision and involving the students in the process. These activities were facilitated by using an action research framework.

\subsection{Research question}

The study was guided by a broad research question, 'How useful was a modified version of the reflective approach to teaching practice debriefing (RATPD) strategy in encouraging postgraduate dissertation students' deep reflection-on-learning. Primarily what they learned about research writing and dissertation supervision?

\subsection{Participants}

The participants for this study were two postgraduate students at the University of Bristol UK. They recently completed their master's dissertation. The participants were Nathan and Delilah (pseudonyms). The production of a dissertation was a very important part of their education and training and is a requirement for the completion of the master's degree in education at the university.

In selecting the students for the study, I used purposeful convenience or opportunity sampling - they were my students - and considered them "information- rich." Guba and Lincoln (1998) state that "information-rich participants" can illuminate or provide a great deal of insight into the issues of importance to any research. An examination of the findings and the responses of the participants reveal that they were able to provide in-depth, relevant, and unique perspectives on the research issue.

\subsection{Data Collection and Ethical Issues}

Participants were invited to take part in the study via a face-to-face meeting. They were told about the nature of the research and how the data would be utilized and promised anonymity. They were also told that their names would not be included in the report. This was adhered to, for no mention of their correct names is made in this report. Both agreed to participate. After submitting their dissertation, they were given the three reflective questions and told to take a few weeks to think critically about the questions and to formulate their responses. They were to email their response to me, which they did, within a week.

\subsection{Data Analysis Process}

The responses to the questions were analyzed using content analysis aided by the Nvivo software. This meant that an analysis was done on each participant's views, as was a cross-examination of emerging categories to discern findings common to all. I also used direct interpretation of the data, which involved looking at each and drawing meaning from the responses (Creswell, 1998 and Powell and Renner, 2003). Essentially, I read through the responses to the three questions asked and found the ideas that recurred. These ideas and words became the main categories or themes (Creswell, 1998; Powell \& Renner, 2003).

For example, an examination of the responses to reflective question 1 revealed words and phrases such as 'writing that clearly communicates' being organised' 'knowing the research purpose or aim', 'planning' 'logical writing' and 'challenges to writing'. From these and others I created a main category 'Mechanics of research writing and dissertation supervision'. Responses to reflective question 1 also include words and phrases such as 'feeling frustrated' 'motivation-draining', 'keeping calm', 'going for holidays', 'encouragement from supervisor' and 'being shown the way', from these I created another main category, 'The affective of research writing and dissertation supervision.

Responses to reflective question 2 revealed phrases such as 'learning along the way' and 'forming beliefs' which suggest that beliefs, values and assumptions were being developed. Responses also include words and phrases such as ', 'I now realise that...' I now know that' and 'this as caused changes in these areas to a great extent' which suggest that beliefs, values and assumptions were changed.

Responses to reflective question 3 revealed words and phrases such as 'patience and calm', 'I should be more realistic' and 'there is still a gap between me and a real researcher'. From these and others, I created the category of criticality and internalisation. From this process of analysis, I constructed an understanding of the usefulness of the modified RATPD strategy in encouraging postgraduate dissertation students' deep reflectionon-learning primarily, what they learned about research writing and dissertation supervision.

\section{The usefulness of a modified RATPD (Results and Discussion)}

I use the three reflective questions as a template to guide this section of the paper. 
5.1. From your recent research writing and supervision experience, what have you learned about each aspect i.e., research writing and supervision?

Examination of the responses to this reflective question reveals its usefulness in two ways. Firstly, the question revealed what participants learned about the mechanics of research writing and dissertation supervision. This includes understanding various research elements (tradition or paradigm of reporting research, logical research writing, literature review, methodology and mastery of the language); research planning (pliable, difficulty, piloting); purpose and organisation and communicating ideas clearly through writing.

My first impression is that research writing is different from essays. There is a tradition or paradigm of reporting research and it involves logical writing. To design and conduct feasible research, I put much effort into the literature review and my supervisor helped me a lot on methodology. The two parts are important for research writing as well, serving as a conceptual framework (Delilah).

About research, I have learned that it should be carefully planned. At the same time, it is impossible to foresee all the aspects of it, I mean, how it will go in reality, so the researcher should be ready to adjust and even change the design of the research if needed. Piloting is essential to check if everything goes the way it has been planned (Nathan).

Research should be done with purpose. I had not understood that before, although I have worked with scientists in a previous job. By purpose I mean, the researcher should clearly understand why he/she does the research and what he/she wants to achieve. Otherwise, everything is just blurred and starts to break into random parts which are not connected, and you might be just lost. Being organized is core when doing research. It should be carried out step by step, and every step should take you closer to your purpose (Nathan).

The need for postgraduate research students to develop knowledge and understanding of the mechanics of research writing and dissertation supervision is a theme and area of discussion in the literature. For example, Lategan (2014) is of the opinion that - among many things - the education and training of researchers (including postgraduate students) should aid them to understand the formal research process. Maunder, GordonFinlayson and Callaghan (2012) argue that the supervision of qualitative master's dissertations should be seen as an apprenticeship into qualitative research. This, by extension, suggests the need to understand the mechanics of the research writing and dissertation supervision process and Dowling, Gorman-Murray, Power, \& Luzia (2012) state that doctoral education is central not just to the production of knowledge but to producing the next generation of researchers and here too I will add, who has knowledge of the mechanics of the research writing and dissertation supervision process.

It is obvious from the responses that participants in this study gained knowledge about the mechanics of research writing and dissertation supervision. However, without the opportunity to surface this knowledge via reflection, what was learned and known would have remained at the students' subconscious level.

An area of developing interest in the research literature, subsumed under the category of the mechanics of research writing and dissertation supervision and raised by one participant, is that of the writing challenges faced by international students in the UK and elsewhere whose 'mother tongue' is not English. The UK hosts 432,001 inbound international students while sending 34,025 British students overseas in 2016 (United Nations Educational, Scientific, and Cultural Organisation, 2016).

...The mastery of language is demanding in research writing. English is not my mother tongue. Sometimes it is hard for me to hit the target words of what I want to express in research writing. Or, I cannot write in an appropriate way, for example, to use the proper academic literacy, when to use the first-person pronoun and when not to, etc. (Delilah).

Aside from the fact that reflective question 1 resulted in Delilah surfacing her knowledge via reflection in this area, her thoughts here seems to give credence to that of Li and Vandermensbrugghe (2011) who raised the alarm that there is evidence that writing support is particularly needed for international research students who have to tackle the challenges of thesis writing in English as their second language in Western academic settings. $\mathrm{Li}$ and Vandermensbrugghe (ibid) suggest the use of writing groups to provide ongoing support to international research students in a cooperative peer learning environment and offers some ways this could be achieved.

Secondly, reflective question 1 also revealed what participants learned about the affective of research writing and dissertation supervision. They used words and phrases such as 'frustration' 'motivation-draining', 'it feels like disaster' 'supporting supervisor', 'taking a break- going for holidays' 'keeping calm and focus' which all point to the emotions associated with research writing and dissertation supervision, well-being, disposition and the need for support. A quotation from Nathan brings to light the emotionality of the process. He states:

Research [can be] frustrating and motivation-draining. I mean, when the survey or interviews are done and suddenly there is a suspicion that the questionnaire or interviews need to be done again because there were some poorly designed questions, it feels like a disaster. Because you have put so much effort into making [the] people complete the questionnaire that you don't really want to do it again (Nathan). 
Nathan goes on to point out the need to attend to one's well-being and having an appropriate disposition by making the point that it is important 'to take a break-go on holidays' for doing so helps to 'freshen' the mind and that he has learned to 'keep calm and focus and just do the job even if there is so much information to get through that at times seems even impossible to do' (Nathan).

Both Nathan and Delilah learned about the need for supportive supervision, not just in aiding students to understand the mechanics of the research process but to engage in supporting them emotionally.

About supervision, I have learnt that it's aimed at academic support. I mean, the supervisor helps the upcoming researcher to respond to the demands of the academic world, for instance, what are the rules of writing, of conducting the research, of presenting it to other academics. However, I have realized, that supporting involves encouraging the student to keep going. Of course, the supervisor should not be a 'mum' but he/she should help by giving advice and helps the students from getting lost because not knowing is the scariest thing. So, the supervisor shows the way, eliminating the unknowing parts (Nathan).

Professors who are chosen to supervise dissertations are important to students' research writing as well. I'm lucky that my supervisor teaches me and encourages me a lot in this process. Some of my classmates seldom hear from their supervisors, who are too busy to conduct the responsibility of supervision (Delilah).

Schulze (2011) researching - among many things - the encouragement and emotional support received by research students in a South African University state that this should include actions such as sandwiching criticism between positive comments, i.e., starting and ending written feedback given to students with positive comments. These are actions - as a dissertation supervisor - to which I am personally committed, vehemently practice and encourage all supervisors to employ, as appropriate.

5.2. To what extent has your recent research writing and supervision experience caused changes in your beliefs, values and assumptions about these aspects i.e., research writing and supervision?

The second question asked about changes to beliefs, values, and assumptions about research writing and dissertation supervision. The examination of the responses to this reflective question reveals its usefulness in that it encouraged participants to think affectively, by targeting their values, beliefs, and assumptions concerning research writing and dissertation supervision.

One participant pointed out that the experience greatly changed her beliefs, values, and assumptions about research writing and dissertation supervision.

To a great extent. Firstly, I now realise that I should never be too optimistic or ideal when I write about research. Research writing is another tough work after conducting actual research. Secondly, not all can become researchers and not all researchers can write well about their research. Research writing could also be engaging (Delilah).

For supervision, a student should and could depend on the supervisor, who is the one that assures the former is moving in the right direction. However, the student should not wait to be fed. Instead, he or she should investigate independently in a proposed direction. The supervision is actually like a beacon for boats in the sea. Also, different supervisors may have their preferred styles of supervision. It is not wise for students to compare horizontally. The allocation is random. Students should focus on how to achieve supports from their supervisors and write well about their research (Delilah).

Nathan, on the other hand, pointed out that the process aided his development of beliefs, values and assumptions about research writing and supervision. He stated, 'I had no beliefs or assumptions about both areas as I had never done research before. But to be honest, I really didn't expect anything - I just did as it was going, learning on my way and forming my beliefs on this way too' (Nathan).

5.3. What have you learned about 'yourself' as researcher?

The third question asked was, 'what have you learned about "self" as researcher?' Examination of the responses to this reflective question reveals its usefulness, in that it encouraged participants to be self-critical and internalise, that is, to identify attitudes or behaviours as a part of their nature (internalisation) (Jarvis, 1996).

After I achieved the phased objective of writing my dissertation, I enjoyed the process. It was a fruitful process from research design to product presenting, although there are also several times of frustration. I have some personalities of a researcher, but not all. There are still gaps between me, an apprentice, and real researchers. If I were to become a researcher, I would like to conduct collaborative research instead of working alone. As research is a lonely career, it would be better if I had my alliance. I would be a perfect partner in the team (Delilah).

I liked that I was very patient and calm, that I started in advance, that I decided to do difficult research although I had doubted this because it seemed very complicated compared to those which my classmates were doing... However, as a researcher, I should be more realistic. I have learnt that as a researcher I 
would like to do research but at the same time to be able to tell about it to those who can use the results of my work. What I liked about myself is that I was very organized, and I could manage a lot of data. However, here I should give credits to my previous work experience - I was a journalist and a science journalist. So, I have learnt that as a researcher I like to make my research trustful and credible. I want it to be bulletproof! Overall, I am satisfied with my attitudes and approaches to being a researcher (Nathan).

These quotations confirmed that participants were encouraged to internalise the experience of research writing and dissertation supervision through a question concerning 'self'.

\section{How useful was the modified RATPD strategy in encouraging postgraduate dissertation students' deep reflection-on-learning?}

The presentation and discussion of findings demonstrate:

- Reflective question one encouraged participants to reveal what they learned about the mechanics and affective of research writing and dissertation supervision;

- Reflective question two encouraged participants to think affectively by targeting their beliefs, values, and assumptions in relation to research writing and dissertation supervision;

- Reflective question three encouraged participants to be self-critical and internalise i.e., identifying and taking ownership of positive attitudes and behaviours as a part of their nature.

\section{Conclusions and Limitation}

The study was guided by a broad research question, 'How useful was a modified version of the reflective approach to teaching practice debriefing (RATPD) strategy in encouraging postgraduate dissertation students' deep reflection-on-learning. Primarily what they learned about research writing and dissertation supervision?

The results proved that the modified RATPD strategy aided in encouraging postgraduate dissertation students' deep reflection-on-learning. It also encouraged students to not only focus on the mechanics of the research writing and dissertation supervision (as important as this is), but also to consider the affective and 'self as student and researcher', which are major facets of deep reflective learning. These results confirm Minott's (2012) conclusion that the RATPD is a useful reflective evaluation strategy.

For reflective dissertation supervisors who engage in, and benefit from a critical assessment of their supervisory capability, the RATPD strategy should be an integral part of their repertoire. This is so because it is another way to get their students to feedback and by reflecting on the feedback enable them to determine what aspects of their supervisory capability are suitable and what may need attention to become more effective (Pearson and Brew 2002).

When considering this study and its contributions, the following limitation must be borne in mind. The study examines the use of a modified version of the RATPD strategy to evaluate learning from a narrow perspective, that is, one supervisor and two postgraduate dissertation students. While this narrow perspective made the study both manageable and achievable, it precludes large-scale generalization of the findings. However, readers are left to make own judgement regarding generalization.

\section{References}

Albertyn, R.M and Bitzer, E.M (2011). Alternative approaches to postgraduate supervision: a planning tool to facilitate supervisory processes. South African Journal of Higher Education 25(5) 875-888

Bryant, K. (1992). Integrated language arts package makes a connection with kindergartners. T. H. E. Journal, 20(4), 47-49.

Creswell, J. H. (1998). Qualitative inquiry and research design choosing among five Traditions. London: Sage Publishing International.

Descombe, M. (1998). The good research guide: For small scale research projects. Buckingham: Open University Press.

Dowling, R., Gorman-Murray, A., Power, E., \& Luzia, K. (2012) Critical Reflections on Doctoral Research and Supervision in Human Geography: The 'PhD by Publication', Journal of Geography in Higher Education, 36 (2), 293-305, DOI:10.1080/03098265.2011.638368

Ferris, D., \& Hedgcock, J. S. (1998). Teaching ESL composition: Purpose, process, and practice. Mahwah, NJ: Lawrence Erlbaum Associates.

Gomez, R., \& Rico, L. (2007). Learning within communities for practice in pre-service secondary school teachers' education. PNA, 2(1), 17-28.

Guba, E. G., \& Lincoln, Y. S. (1998). Competing paradigms in qualitative research. In N. K. Denzin \& Y. S. Lincoln (Eds.), The landscape of qualitative research: Theories and issues (pp. 105-107). Thousand Oaks, CA: Sage.

James-Reid, O. (1983). Teaching, its management and function. Kingston, JA: Kingston Publishers. Jarvis, P. (1996). Adult \& continuing education Theory and practice (2nd Ed.). London: Routledge. 
Lategan, L.O.K. (2014). "Research education": a concept wider than postgraduate supervision? Journal for New Generation Sciences, 12(2), 43-58.

Li, L., and Vandermensbrugghe, J (2011). Supporting the thesis writing process of international research students through an ongoing writing group. Innovations in Education and Teaching International 48 (2)195-205

Long, D. G. (1990). Learner managed learning: The key to lifelong learning and development. London: Kogan Paul.

Maunder, R.E., Gordon-Finlayson, A. and Callaghan, J. (2012) Behind Supervisory Doors: Taught Master's Dissertation Students as Qualitative Apprentices. Psychology Learning \& Teaching, 11(1), 30-38

McCulloch, A. (2009). The student as co-producer: Learning from public administration about the studentuniversity relationship. Studies in Higher Education, 34(2), 171-183.

Merriam, S. B., \& Caffarfella, R. S. (1999). Learning in adulthood. San Francisco, CA: Jossey-Bass.

Minott. MA. (2012). A Reflective Approach to Teaching Practicum Debriefing. Teacher Education and Practice 25 (2) 287-301.

Naydene, D., Guruvasagie, P., and Vitallis. C. ( 2011)., Doctoral learning : a case for a cohort model of supervision and support. South African Journal of Education, 31(1) 15-30.

Pearson, M., \& Brew, A. (2002). Research training and supervision development. Studies in Higher Education, $27,135-150$.

Powell, E. T., \& Renner, M. (2003). Analyzing qualitative data. University of Wisconsin- Extension USA. Retrieved from http://learningstore.uwex.edu/pdf/g3658-12.pdf.

Rowe, G. N. (1984). Teaching \& learning. Kingston, JA: University of Technology Technical Education Department.

Schön, D. A. (1983). Reflective practitioner. New York, NY: Basic Books.

Schulze, S. (2011). A survey of students' views of supervision at Unisa. South African Journal of Higher Education, 25(4) 784-802.

Sparapani, E. F. (2000). The effect of teaching for higher-level thinking: An analysis of teacher reactions. Education, 121(1), 80.

United Nations Educational, Scientific and Cultural Organisation. (2016). Global Flow of Tertiary-Level Students. UNESCO Institute of Statistics. Retrieved July 13, 2019 from http://uis.unesco.org/en/uis-studentflow

Vilkinas, T. (2008). An Exploratory Study of the Supervision of Ph.D./Research Students' Theses. Innovative Higher Education,32 (5), 297-311

Yousefl, A., Bazrafkan, L., and Yamani, N. (2015). A qualitative inquiry into the challenges and complexities of research supervision: viewpoints of postgraduate students and faculty members. Journal of Advances in Medical Education and Professionalism, 3(3), 91-98

Zeichner, K. M., \& Liston, D. P. (Eds.). (1996). Reflective teaching: An introduction. Mahwah, NJ: Lawrence Erlbaum Associates. 